evidence against DDT, for instance its link with declining bird populations such as that of the peregrine falcon, was sufficient to have the chemical declared an environmental pollutant for the purposes of regulation.

The EDF won its case. A sympathetic judge agreed that the evidence against DDT was sufficiently damning, and that there was no identifiable level beneath which DDT could be claimed to be completely harmless, a conclusion which undoubtedly contributed to the EPA's decision to phase out the chemical in 1972. Yet as much as the verdict itself, it was the publicity generated by the court case that provided some of the most effective spinoff. For it helped to generate a wave of public support for strict environmental laws - such as NEPA - that sympathetic legislators were quick to pass through Congress.

Industry, too, learnt its lesson from the Wisconsin hearing. The National Agricultural Chemicals Association initially sent only one retired attorney, a former counsel for the Velsicol Chemical Corporation, to present its defence of DDT. Having little reason to doubt that the arguments about the lack of evidence of DDT's harmfulness, which had proved successful in previous government regulatory proceedings, would again prevail, he was unprepared for either the style or the strength of the environmentalists' carefully-prepared attack. Even if it was a public relations battle, the symbolism of the loss in Wisconsin had to be taken seriously - a message which the chemical industry gradually took to heart during the 1970s.

The path seen in the struggle against DDT, culminating in hearings before the Environmental Protection Agency in 1971 and its eventual ban by EPA administrator William D. Ruckelshaus, was soon to become familiar. A similar process led to the ultimately-successful efforts by residents of Wisconsin's neighbouring state, Minnesota, to stop the Reserve Mining Company from discharging waste tailings from its taconite mill directly into Lake Superior, the largest inland sea in the Western Hemisphere.

In The Reserve Mining Controversy: Science, Technology and Environmental Quality, Robert V. Bartlett describes how the final outcome of that campaign, fought in various state and federal courts over a period of more than ten years, was as much the result of changing public perceptions as a neutral assessment of scientific evidence that the tailings discharged into the lake were causing harm.

The parallels with the DDT campaign are close. Just as the first critics of DDT based their case on the environmental effects of the pesticide which much of public opinion could dismiss as relatively harmless, so the first complaints against Reserve Mining, which had been given permission to discharge its tailings into the lake when building its plant in 1947, focused on the discoloration of the water that the discharge appeared to cause, even though there was no direct evidence that the discoloration was causing significant biological damage.

Similarly, just as the final nail in DDT's coffin was the discovery early in 1969 that the chemical was a potential human carcinogen, so the federal order requiring Reserve Mining to find a land-based depository for its tailings - the result of a drawn-out suit against the company filed by the Department of Justice at the instigation of the EPA - hinged on the close morphological similarity between particles in the taconite tailings and asbestos fibres which scientists were beginning to demonstrate posed a significant hazard to health.

Bartlett, like Dunlap, provides a useful account of the twists and turns of the legal proceedings. The Reserve Mining controversy provides, as he points out, perhaps one of the most dramatic examples of the difficulties facing courts that are asked to decide on relatively complex scientific issues with legal equipment often ill-suited to the task. Each side in the dispute exploited the ambiguity of evidence about the environmental and health effects of the taconite waste to its own advantage, applying criteria of "truth" and "legitimacy" entirely foreign to conventional scientific discourse. As Bartlett points out, the dilemmas faced by the courts on such issues are partly the result of built-in tendencies of the political system in the United States to try to resolve conflict through adversary litigation rather than consensus-based planning. Dunlap, however, goes further to argue that the environmental problems raised by persistent pesticides such as DDT are not merely the result of unthinking industrial growth, or shifting public perceptions, but have deeper social and political roots. Among these, he suggests, is a "technicalfix" mentality to pest control that was reinforced by the professional self-image of economic entomologists, physicians' concepts of health and disease, and the economic motivations of farmers and pesticide manufacturers.

The significance of this message is unlikely to disappear. The climate of public opinion has changed since the days when the environmentalist movement was at its height, yet the change may not be as dramatic as many in the Reagan administration would like to believe. Plans to overhaul the Clean Air Act, for example, offered as a pre-election promise to the auto industry in 1980, have been postponed largely on the grounds that the political price in terms of lost popular support would be too high. Rather than abandoning the ideal of environmental protection, the administration is seeking more subtly to change the ground-rules.

The lesson of both of these books is the need to treat semantics warily. In both the DDT and the Reserve Mining disputes, the struggle over the proper treatment of the natural environment became clothed, for legal purposes, in a scientific language that as often seemed to obscure as clarify the real nature of the conflict. The problem is not unique to the United States, but it tends to be exacerbated in a country where, as one social scientist recently put it, "the gap between political ideal and political reality is a continuing central phenomenon".

David Dickson was Washington News Editor for Nature from 1977 to 1982.

\section{AI in chemistry}

\section{R. Venkataraghavan}

Applications of Artificial Intelligence for Organic Chemistry: The Dendral Project. By Robert K. Lindsay et al. Pp.194. ISBN 0-07-037895-9. (McGraw-Hill: 1981.) $\$ 39.50$, £19.95.

Applications of Artificial Intelligence for Organic Chemistry provides an excellent overview of a discipline that is playing an increasingly important role in problemsolving techniques using computers. The volume takes the reader through the definition of a problem in organic chemistry, concepts of advanced computer techniques, applications and, finally, to some interesting observations and conclusions of the authors. The applications cited in the book represent the research carried out by a team of interdisciplinary scientists, and provide some unusual and thoughtprovoking perspectives on the promise of computing in this area.

Emphasis is placed on the utilization of spectrochemical data and Dendritic Algorithms for structure-elucidation problems. The evolution of the Dendral project and its current capabilities clearly show the potential of computer-based techniques in the symbolic manipulation of complex information. The application of these techniques, however, is not confined to organic chemistry; in time they will undoubtedly be used to tackle a number of other problems in applied science. Certainly, the discussions of design considerations and the choice of computer-based tools should benefit those readers involved in the development of a variety of complex software projects.

This concise volume, representing the fruits of several years of active research, will prove to be a valuable source book for all seriously interested in the applications of computer techniques to problems in organic chemistry. It is to be hoped, too, that its influence will spread to associated disciplines and beyond.

R. Venkataraghavan is the Manager of the Research Applications Development Department at Lederle Laboratories, Pearl River, New York. 